\title{
KEKUATAN SERTA SYARAT KEABSAHAN CCTV SEBAGAI ALAT BUKTI DIDALAM SUATU PERSIDANGAN DITINJAU DARI KUHAP
}

\author{
Oleh \\ Enik Isnaini \\ ${ }^{2}$ Dosen Fakultas Hukum Universitas Islam Lamongan
}

\begin{abstract}
ABSTRAK
pengaturan kekuatan CCTV sebagai alat bukti dalam suatu persidangan setelah lahirnya Undang-Undang Nomor 11 Tahun 2008 Informasi dan Transaksi Elektronik dan Undang-Undang Nomor 19 Tahun 2016 tentang perubahan atas Undang-Undang Nomor 11 Tahun 2008 tentang Informasi dan Transaksi Elektronik untuk membantu memperluasan jumlah alat bukti yang diatur dalam KUHAP dan juga memperluas cakupan alat bukti yang diatur dalam KUHAP. CCTV memiliki peranan sebagai alat bukti yang sah dalam suatu persidangan sehingga memiliki kedudukan yang sangat penting dalam suatu persidangan sebagai suatu alat bukti untuk mengungkap suatu kejadian perkara yang telah terjadi sebelumnya sehingga dapat meyakinkan hakim dalam mempertimbangkan dan memberikan putusan yang adil kepada para pihak.

Informasi Elektronik dan/atau Dokumen Elektronik dinyatakan sah apabila menggunakan Sistem Elektronik yang memenuhi persyaratan minimum sebagai berikut (pasal 5 ayat (3) jo. Pasal 6 UU No. 11/2008).Penelitian ini menggunakan metode normatif deskriptif dimana data primer dan data sekunder yang diperoleh dianalisis secara kualitatif dan kemudian dideskriptifkan. Hasil penelitian menunjukan adanya peran CCTV yang sangat penting dalam pembuktian tindak pidana. dimana penggunaanCCTV tersebut sebagai alat bukti penunjang terhadap alat bukti sah yangberupa Keterangan Saksi, Keterangan Ahli, Surat, Petunjuk dan KeteranganTerdakwa. Rekaman CCTV dapat menunjukan bagaimana kejadiansesungguhnya yang terjadi pada setiap kejadian tindak pidana. Sedangkan kendala yang dihadapi berupa kendala hukum, CCTV belum begitu jelas didalam KUHAP sehingga kejelasaan CCTV sebagai alat bukti yang sah ada di dalam UU Nomor 11 tahun 2008 tentang UU ITE yang memperjelas status CCTV sebagai alat bukti, dan kendala non hukum yakni adanya hasil editing dariRekaman CCTV serta hasil Rekaman CCTV sangat dipengaruhi kualitas darikamera CCTV.
\end{abstract}

Kata Kunci: keabsahan CCTV, alat bukti, KUHAP

\section{A.Pendahuluan Latar belakang}

CCTV adalah satu media yang dapat digunakan untuk memuat rekaman setiap informasi yang dapat dilihat, dibaca dan didengar dengan bantuan sarana adalah CCTV. CCTV dijadikan sebagai alat bukti yang sistemnya menggunakan video camera untuk menampilkan dan merekam gambar pada waktu dan tempat tertentu dimana perangkat ini terpasang yang berarti menggunakan signal yang bersifat tertutup, tidak seperti televisi biasa yang merupakan broadcast signal. Pada umumnya CCTV digunakan sebagai pelengkap 
sistem keamanan dan banyak dipergunakan di berbagai bidang seperti militer, bandara, toko, kantor dan pabrik. Bahkan pada perkembangannya, CCTV sudah banyak dipergunakan di dalam lingkup rumah pribadi. Namun untuk mengungkap kejahatan yang berkaitan langsung dengan CCTV yang menjadi alat bukti dalam suatu kasus yang mulai tengah marak terjadi. Perkembangan kriminalitas atau tindak pidana dalam masyarakat yang sedang mengalami modernisasi meliputi masalah-masalah yang berhubungan dengan frekuensi kejahatan, kualitas kejahatan, dan kemungkinan melaksanakan, menandakan, menyaksikan dan meyakinkan.

Menyikapi keadaan ini, maka tantangan-tantangan yang muncul

\section{Metode Penelitian}

\section{Type Penelitian}

Penelitian Hukum Normatif atau metode penelitian hukum kepustakaan adalah metode atau cara yang dipergunakan di dalam penelitian hukum yang dilakukan dengan cara meneliti bahan pustaka yang ada.

\section{Pendekatan Masalah}

Rekaman CCTV yang dijadikan alat bukti di dalam persidangan kasus kematian Wayan Mirna Salihin dengan terdakwa Jessica Kumala Wongso bisa dinyatakan tidak sah. Hal ini jika merujuk kepada putusan Mahkamah Konstitusi (MK)No.20/PUU-XIV pada tanggal 7 September 2016. ${ }^{47}$ Pendapat ini harus dihadapi bahkan dicari jalan keluarnya, terlebih terhadap munculnya modus-modus kejahatan yang menggunakan teknologi informasi ini. Sehubungan dengan itu, kasus-kasus yang terjadi yang bersentuhan dengan teknologi informasi dan telekomunikasi khususnya menyangkut media video recorder kamera CCTV, sudah mulai marak diperbicangkan di masyarakat, sehingga penggunaannya dalam mengungkap kejahatan atau sebagai sarana pendukung dalam membuktikan tindak pidana akan berhadapan dengan keabsahannya sebagai alat bukti yang sudah tentu akan berbenturan dengan instrumen hukum yang ada mengingat bahwa pembuktian dalam kasus tindak pidana dengan alat bukti yang digunakan ialah alat bukti CCTV disampaikan pengacara kondang Hotman Paris. Dia mengatakan, rekaman baru dikatakan sah manakala ada permintaan dari penegak hukum. "Ternyata CCTV Kafe Olivier dibuat bukan atas permintaan penyidik, maka sesuai putusan MK CCTV Kafe Olivier tersebut tidak sah sebagai alat bukti,"

\footnotetext{
${ }^{47} \mathrm{http} / /$ metro.sindonews.com/read/1145171/170/p utusan-mk-hotman-paris-cctv-tidak-bisa-jadi-alatbukti-1475761524Diakses pada 01 mei 2017 pukul 01:45
} 


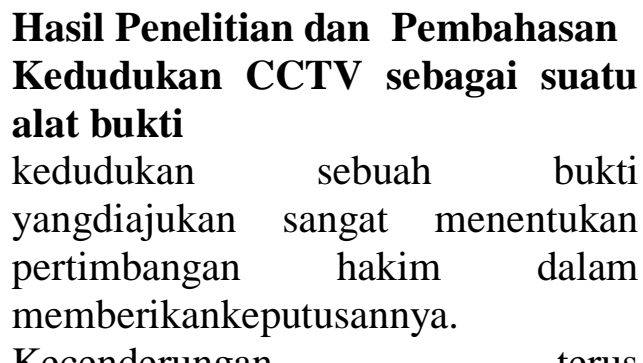

Kecenderungan terus berkembangnya teknologi membawa berbagaiimplikasi yang harus diantisipasi dan diwaspadai, maka terdapat upaya yangtelah melahirkan suatu produk hukum dalam bentuk Undang-Undang No.11 Tahun 2008 Tentang Informasi dan Transaksi Elektronik. Namun denganlahirnya Undang-Undang tersebut belum semua permasalahan menyangkutmasalah Informasi dan Transaksi Elektronik dapat ditangani. Persoalantersebut antara lain dikarenakan:

$\begin{array}{llr}\text { Dengan } & \text { lahirnya } & \text { Undang-Undang } \\ \text { No. } & 11 & \text { Tahun }\end{array}$ TentangInformasi dan Transaksi Elektronik tidak semata-mata UndangUndang-Undang ini bisa diketahui oleh masyarakat penggunateknologi informasi dan praktisi hukum;Berbagai bentuk perkembangan teknologi yang menimbulkanpenyelenggaraan dan jasa baru harus dapat diidentifikasi dalamrangka antisipasi terhadap pemecahan berbagai persoalan teknisyang dianggap baru sehingga dapat dijadikan bahan untukpenyusunan berbagai peraturan pelaksana;Pengayaan akan bidangbidang hukum yang sifatnya sektoral(rezim hukum baru) akan makin menambah semarak dinamikahukum yang akan menjadi bagian system hukum nasional. ${ }^{38}$

\footnotetext{
${ }^{38}$ Ahmad M Ramli. 2008. Dinamika Konvergensi Hukum Telematika Dalam System Hukum
}

Perkembangan membuat klasifikasi mengenai barang bukti semakinkompleks, jika mengacu pada Undang-Undang No. 11 Tahun 2008 TentangInformasi dan Transaksi Elektronik, maka terdapat sebuah barang buktielektronik dan barang bukti digital sebagai berikut:

Barang bukti Elektronik, jenisnya meliputi:

a. Computer PC, laptop/notebook, netbok, tablet;

b. Handphone, Smartphone;

c.Flashdisk/thumbdrive;

d. Floppydisk;

e. Harddisk;

f. $C D / D V D$;

g. Router,Swich; hub;

h. Kamera Video, CCTV;

$i$. Kamera Digital;

j. Music/Video Player, dan lain-lain.

Barang Bukti DigitalBarang bukti dalam Undang-Undang No. 11 Tahun 2008 TentangInformasi dan Transaksi Elektronik dikenal dengan istilah InformasiElektronik dan Dokumen Elektronik, contohnya:

a. Logical File, yaitu file-file yang masih ada dan tercatat di file system yang sedang berjalan di suatu partisi;

b. Deleted file;

c. Lost file;

d. File slack;

e. Log file;

$k$. Image file;

l. Email;

m. User ID dan Password;

n. Short Message Service (SMS);

o. Multimedia Message Service (MMS);

p. Call $\underset{39}{\log s .}$

${ }^{39}$ Mohammad Nuh Al-Azhar. Op.Cit. Hlm. 27-29 


$\begin{aligned} & \text { Rekaman Video CCTV } \begin{array}{r}\text { dapat } \\ \text { digolongkan }\end{array} \\ & \text { informasielektronik } \\ & \text { dan/atau } \\ & \text { dokumen elektronik }\end{aligned}$
$\begin{aligned} & \text { Undang-Undang No.11 Tahun } 2008 \\ & \text { berdarkan }\end{aligned}$
$\begin{aligned} & \text { Tentang Informasi dan } \\ & \text { Elektronik, }\end{aligned}$
yangtercantum pada Pasal 1 ayat (1)
dan ayat (4), yang merumuskan bahwa:

"Informasi Elektronik adalah suatu atau sekumpulan data elektronik,termasuk tetapi tidak terbatas pada tulisan, suara, gambar, peta,rancangan, foto, Electronic Data Interchange (IDE), surat elektronik(electronic mail), telegram, teleks, telecopy atau sejenisnya, huruf,tanda, angka, kodem akses, simbol atau perforasi yang telah diolahyang memiliki arti atau dapat dipahami oleh orang yang mampumemahaminya."

Pasal 1 ayat (4), yang merumuskan:

"Dokumen Elektronik adalah setiap informasi elektronik dibuat, diteruskan, dikirimkan, diterima, atau disimpan dalam bentuk analogdigital, elektromagnetik, optikal, atau sejenisnya yang dapat dilihat,ditampilkan, dan/atau didengar melalui komputer atau systemelektronik termasuk tetapi tidak terbatas pada tulisan, suara, gambar,peta, rancangan, foto, atau sejenisnya huruf, tanda, angka, kodeakses, simbol atau perforasi yang memiliki makna atau arti ataudapat dipahami oleh barang yang mampu memahaminya."

Ketentuan dalam Pasal 5 ayat (2) Undang-Undang No. 11 Tahun2008 Tentang Informasi dan Transaksi Elektronik menegaskan bahwa :

$\begin{array}{ccc}\text { "Informasi elektronik } & \text { dan/atau } \\ \text { dokumen elektronik } & \text { dan/atau }\end{array}$
$\begin{array}{lr}\text { hasilcetakannya } & \text { sebagaimana } \\ \text { dimaksud pada } & \text { ayat }\end{array}$ sebelumnya,merupakan perluasan dari alat bukti yang sah sesuai dengan hukumacara yang berlaku di Indonesia."

Ketentuan Pasal 5 Undang-Undang No. $11 \quad$ Tahun 2008 TentangInformasi dan Transaksi Elektronik, merumuskan bahwa:

(1)Informasi Elektronik dan/atau Dokumen Elektronik dan/atau hasilcetaknya merupakan alat bukti hukum yang sah.

(2)Informasi Elektronik dan/atau Dokumen Elektronik dan/atau hasilcetaknya sebagaimana dimaksud pada ayat (1) merupakanperluasan dari alat bukti yang sah sesuai dengan Hukum Acarayang berlaku di Indonesia.

(3)Informasi Elektronik dan/atau Dokumen Elektronik dinyatakansah apabila menggunakan Sistem Elektronik sesuai denganketentuan yang diatur dalam Undang-Undang ini.

(4)Ketentuan mengenai Informasi Elektronik dan/atau DokumenElektronik sebagaimana dimaksud pada ayat (1) tidak berlakuuntuk:

a. Surat yang menurut UndangUndang harus dibuat dalambentuk tertulis; dan

b. Surat beserta dokumennya yang menurut Undang-Undnagharus dibuat dalam bentuk akta notariil atau akta yang dibuatoleh pejabat pembuat akta.

Pasal 44 Undang-Undang No. 11 Tahun 2008 tentang Informasidan Transaksi Elektronik merumuskan: Alat bukti penyidikan, penuntutan dan pemeriksaan di sidangpengadilan menurut ketentuan Undang-Undang ini adalahsebagai berikut: 
a. Alat bukti sebagaimana dimaksud dalam ketentuanPerundang-Undangan;dan b. Alat bukti lain berupa Informasi dan/atau DokumenElektronik sebagaimana dimaksud dalam Pasal 1 angka 1dan angka 4 serta Pasal 5 ayat (1), ayat (2), dan ayat (3).

Pemahaman "perluasan" tersebut dihubungkan dengan Pasal 5 ayat(1) Undang-Undang No. 11 Tahun 2008 Tentang Informasi dan TransaksiElektronik

Pasal 1 ayat (4), yang merumuskan:

"Dokumen Elektronik adalah setiap informasi elektronik dibuat,diteruskan, dikirimkan, diterima, atau disimpan dalam bentukanalog digital, elektromagnetik, optikal, atau sejenisnya yang dapatdilihat, ditampilkan, dan/atau didengar melalui komputer atausistem elektronik termasuk tetapi tidak terbatas pada tulisan, suara,gambar, peta, rancangan, foto, atau sejenisnya huruf, tanda, angka,kode akses, simbol atau perforasi yang memiliki makna atau artiatau dapat dipahami oleh barang yang mampu memahaminya."

Pengertian dalam Pasal 1 ayat (4) Undang-Undang No. 11 Tahun2008 Tentang Informsi dan Transaksi Elektronik diatas, rekaman videoyang terdapat dalam CCTV digolongkan menjadi dokumen elektronik,karena:

- Rekaman Video CCTV merupakan Informasi Elektronik;

- $\quad$ Rekaman Video CCTV yang dibuat, diteruskan, dikirimkan,diterima, atau disimpan dalam bentuk analog digital,elektromagnetik di sebuah kamera CCTV;
- $\quad$ Rekaman Video CCTV dapat dilihat, ditampilkan dandidengar melalui komputer atau sistem elektronik yang lain;

- Rekaman Video CCTV memiliki makna atau artiBerdasarkan penjelasan diatas, rekaman video CCTV dapatdigolongkan menjadi informasi elektronik dan dokumen elektronik, maka rekaman video dalam CCTV dapat menjadi alat bukti yang sah di depanhukum/pengadilan25.

Syarat Sahnya Suatu Alat Bukti CCTV

Elektronik yang memenuhi persyaratan minimum sebagai berikut (pasal 5 ayat (3) jo. Pasal 6 UU No. 11/2008):

a. dapat menampilkan kembali Informasi Elektronik dan/atau Dokumen Elektronik secara utuh sesuai dengan masa retensi yang ditetapkan dengan Peraturan Perundang-undangan;

b. dapat melindungi ketersediaan, keutuhan, keotentikan, kerahasiaan, dan keteraksesan Informasi Elektronik dalam Penyelenggaraan Sistem Elektronik tersebut;

c. dapat beroperasi sesuai dengan prosedur atau petunjuk dalam Penyelenggaraan Sistem Elektronik tersebut;

d. dilengkapi dengan prosedur atau petunjuk yang diumumkan dengan bahasa, informasi, atau simbol yang dapat dipahami oleh pihak yang bersangkutan dengan Penyelenggaraan Sistem Elektronik tersebut; dan

e. memiliki mekanisme yang berkelanjutan untuk menjaga kebaruan, kejelasan, dan kebertanggungjawaban prosedur atau petunjuk. 


\section{Kesimpulan}

a. Bagaimana pengaturan kekuatan CCTV sebagai alat bukti dalam suatu persidangan setelah lahirnya Undang-Undang Nomor 11 Tahun 2008 Informasi dan Transaksi Elektronik dan Undand-Undang Nomor 19 Tahun 2016 tentang perubahan atas Undang-Undang Nomor 11 Tahun 2008 tentang Informasi dan Transaksi Elektronik untuk membantu memperluasan jumlah alat bukti yang diatur dalam KUHAP dan juga memperluas cakupan alat bukti yang diatur dalam KUHAP.

CCTV memiliki peranan sebagai alat bukti yang sah dalam suatu persidangan sehingga memiliki kedudukan yang sangat penting dalam suatu persidangan sebagai suatu alat bukti untuk mengungkap suatu kejadian perkara yang telah terjadi sebelumnya sehingga dapat meyakinkan hakim dalam

mempertimbangkan dan memberikan putusan yang adil kepada para pihak.

b. Syarat sahnya CCTV sebagai alat bukti dalam suatu persidangan Dalam suatu persidangan suatu alat bukti harus memiliki keaslian dan keutuhan yang terdapat disuatu tepat kejadian perkara sehingga ada syarat agar CCTV menjadi suatu alat bukti yang sah sebagai berikut :

Informasi Elektronik dan/atau Dokumen Elektronik dinyatakan sah apabila menggunakan Sistem Elektronik yang memenuhi persyaratan minimum sebagai berikut (pasal 5 ayat (3) jo. Pasal 6 UU No. 11/2008):

\section{Saran}

a. Mengenai alat bukti sah diluar KUHAP sudah seharusnya diaturatau disusun secara lebih jelas dan tegas guna membantu mengungkapkansuatu kebenaran materiil. Tidak hanya rekaman video CCTV saja tetapi jugamengatur adanya alat bukti digital lainnya, dimana alat bukti digital tersebutmemiliki peranan yang penting dalam suatu pencarian kebenaran materiil danmemberikan keyakinan hakim dalam memutus perkara secara adil. Sehinggareferensi hakim dalam memberikan atau menjatuhkan putusan tidak hanyaterpaku dalam Pasal 184 KUHAP tetapi juga melihat dari pasal-pasal yang terdapat dalam Undang-Undnag lainnya, seperti Undang-Undang No. 11 Tahun2008 Tentang Informasi dan Transaksi Elektronik.

b. Untuk mengurangi kendalakendala dalam penggunaan Kemera CCTVdalam setiap proses di Pengadilan, Kamera CCTV tersebut juga harusdilengkapi dengan teknologi tambahan dalam pemasangan sehinggatidak mudah rusak atau dirusak sehingga rasa keadilan dalammasyarakat dapat terjamin.

c. Dengan majunya teknologi dimasa sekarang salah satunya KameraCCTV diharapkan para penegak hukum dalam hal ini Kejaksaan danKepolisian sebagai pintu masuk pertama dalam pembuktian setiaptindak pidana harus memperkaya kemampuan sumber dayamanusianya sendiri dan mengoptimalkan kinerjanya sehingga dapatmenganalisis dan mengoperasikan setiap teknologi yang telahberkembang di masa sekarang ini.

\footnotetext{
literatur

Luhut MP Pangaribuan. 2005. Hukum Acara Pidana: Surat-surat Resmi di Pengadilan oleh Advocat. Jakarta: Djambatan.
}

Daftar Pustaka 
M. Yahya Harahap. 2002. Pembahasan Permasalahan dan Penerapan KUHAP Pemeriksaan Sidang Pengadilan Banding. Jakarta: Sinar Grafika.

Andi Hamzah, Hukum Acara Pidana Indonesia, Sinar Grafika, Jakarta, 2013

Alfitra. 2011. Hukum Pembuktian dalam Beracara Pidana, Perdata dan Korupsi di Indonesia.Jakarta: Raih Asa Sukses. Hlm.

Ahmad M Ramli. 2008. Dinamika Konvergensi Hukum Telematika Dalam System Hukum Nasional. Jurnal Legislasi Indonesia

Mohammad Taufik Makarao dan Suhasril. 2010. Hukum Acara Pidana Dalam Teori dan Praktek. Bogor: Ghalia Indonesia

\section{Artikel}

http://www.raseko.com/2013/04/pengertianclosed-circuit

http://warungcyber.web.id/?p-84

http://www.raseko.com/2013/04/pengertianclosed-circuit-television.html

http://hukumindonesia.blog.com/2011/04/16/alatbuki-petunjuk-dalam-sidang-pengadilan/ 